\title{
Voltage-Gated Sodium Channel Polymorphism and Metabolic Resistance in Pyrethroid-Resistant Aedes aegypti from Brazil
}

\author{
Ademir Jesus Martins, Rachel Mazzei Moura de Andrade Lins, Jutta Gerlinde Birgitt Linss, \\ Alexandre Afranio Peixoto, and Denise Valle* \\ Laboratório de Fisiologia e Controle de Artrópodes Vetores, Instituto Oswaldo Cruz, FIOCRUZ, Rio de Janeiro - RJ, Brazil; \\ Laboratório de Biologia Molecular de Insetos, Instituto Oswaldo Cruz, FIOCRUZ, Rio de Janeiro - RJ, Brazil; \\ Instituto de Biologia do Exército, Rio de Janeiro - RJ, Brazil
}

\begin{abstract}
The nature of pyrethroid resistance in Aedes aegypti Brazilian populations was investigated. Quantification of enzymes related to metabolic resistance in two distinct populations, located in the Northeast and Southeast regions, revealed increases in Glutathione- $S$-transferase (GST) and Esterase levels. Additionally, polymorphism was found in the IIS6 region of $A$ e. aegypti voltage-gated sodium channel $\left(A a N a_{V}\right)$, the pyrethroid target site. Sequences were classified in two haplotype groups, $\mathrm{A}$ and $\mathrm{B}$, according to the size of the intron in that region. Rockefeller, a susceptible control lineage, contains only B sequences. In field populations, some A sequences present a substitution in the 1011 site (Ile/Met). When resistant and susceptible individuals were compared, the frequency of both A (with the Met mutation) and B sequences were slightly increased in resistant specimens. The involvement of the $A a N a_{V}$ polymorphism in pyrethroid resistance and the metabolic mechanisms that lead to potential cross-resistance between organophosphate and pyrethroids are discussed.
\end{abstract}

\section{INTRODUCTION}

Dengue plagues more than 100 countries inhabited by 2.5 billion people. Every year 20-100 million new cases of classic dengue and 500,000 cases of dengue hemorrhagic fever are responsible for approximately 24,000 deaths. The affected areas are mainly concentrated in tropical and subtropical regions, as dengue is endemic in Latin America, Africa, Eastern Mediterranean, Southeast Asia, and Western Pacific. ${ }^{1}$ In Brazil during the last two decades, dengue has increased both in number and severity of cases, the dissemination of the vector populations, the mosquito Aedes aegypti (Linnaeus, 1792), being the principal cause of this scenario. ${ }^{1,2}$ Aedes aegypti is also the urban yellow fever vector, another disease that threatens the country because of the growing human occupation of sylvatic areas, where the yellow fever virus may circulate. ${ }^{3}$ Dissemination of the mosquito is due in part to the emergence of insecticide resistant populations. However, because an effective dengue vaccine is not yet available, insecticides still play a major role in vector control. ${ }^{4}$ The major classes of insecticides for vector control act on different targets of the central nervous system, leading to malfunctions in nerve impulse transmission and consequent death. Organophosphates (OP) and carbamates bind to the Acetylcholinesterase (ACE) enzyme at the cholinergic synapses. Pyrethroids and the organochlorine DDT have affinity for the $\alpha$-subunit of the voltage gated sodium channel $\left(\mathrm{Na}_{\mathrm{v}}\right)$, preventing its operation and resulting in repetitive firings of nerve cells. ${ }^{5}$

In Brazil, the OP temephos has been used as a larvicide since 1967, with the introduction of pyrethroids (PY) in 2000 for the control of adults. Resistance to both classes of insecticides has developed throughout the country. ${ }^{6-9}$

Two mechanisms are mainly responsible for insecticide resistance. The first is an increased activity of detoxifying enzymes known as metabolic resistance. The key enzymes associated to metabolic resistance are Esterases, Glutathion- $S$-transferases (GST), and Mixed-Function Oxydases (MFOs or P450). The

\footnotetext{
* Address correspondence to Denise Valle, Laboratório de Fisiologia e Controle de Artrópodes Vetores, Instituto Oswaldo Cruz, FIOCRUZ, Av. Brasil 4365, Rio de Janeiro-RJ, CEP: 2104-900, Brazil. E-mail: dvalle@ioc.fiocruz.br
}

second mechanism is a consequence of structural changes in the insecticide target site in the central nervous system, leading to a decreased affinity for the insecticide. ${ }^{10}$

Binding of PY insecticides to $\mathrm{Na}_{\mathrm{v}}$ provoke the phenomenon known as knockdown, defined as "rapid and involuntary movements, followed by paralysis and death."11,12 Phenotype knockdown resistance $(k d r)$ was first documented in a strain of Musca domestica resistant to DDT, ${ }^{13}$ later being established that the $k d r$ phenotype was linked to the $\mathrm{Na}_{\mathrm{v}}$ gene of that species. ${ }^{14,15}$ The same was observed in other insect pests and disease vectors, such as Haematobia irritans, ${ }^{16}$ Heliothis virescens, ${ }^{17}$ Blatella germanica,${ }^{18}$ and Ae. aegypti. ${ }^{19}$

Structurally, the $\mathrm{Na}_{\mathrm{v}}$ has four homologous domains (I-IV), each of which is composed of six hydrophobic segments (S1S6). ${ }^{20}$ The $\mathrm{Na}_{\mathrm{V}}$ sequence is highly conserved among animals, and because of its physiologic role, there are few viable mutations in this molecule. ${ }^{21}$ The $k d r$ phenotype is related to the same point mutation in a variety of species from different orders: the replacement Leu1014Phe (numbering based on the primary sequence from $M$. domestica) in the segment IIS6. ${ }^{22}$ Another mutation (Met918Thr), referred to as super $k d r$, exists always in the presence of the classic $k d r$, and was found in the H. irritans horn fly and in $M$. domestica, increasing pyrethroid resistance more than 1,000 times. ${ }^{23}$ High throughput techniques based on allelic-specific polymerase chain reaction (PCR) and real time PCR have been adopted for the diagnosis of classic $k d r$ mutation in a number of insect species. ${ }^{24-26}$ In addition to this well-known mutation, others have been described in some insect populations resistant to PY and/ or DDT. Nevertheless, in many cases their relation with resistance remains to be determined, as extensively revised. ${ }^{27,28}$

In Ae. aegypti, although the Leu1014Phe substitution has not been found, other replacements in the IIS5-S6 region are reported: Gly923Val, Leu982Trp, Ile1011Met, Ile1011Val, Val1016Ile, and Val1016Gly. ${ }^{29,30}$ The Ile1011Met substitution was found in a Brazilian population from Belém, PA, with low sensitivity to pyrethroid as measured by an electrophysiologic assay. ${ }^{29}$ Nevertheless, selection pressure with pyrethroids in the laboratory strongly suggested that the $k d r$ mutation in $A e$. aegypti is the Val1016Ile. ${ }^{30}$ It was recently reported that the substitution Asp1794Tyr, out of domain II, together with the known Val1016Gly is also related to pyrethroid resistance. ${ }^{31}$ 
We adapted a protocol based on procedures from Centers for Disease Control and Prevention (CDC) and World Health Organization (WHO), ${ }^{32,33}$ which measures changes in the activity of the enzymes involved in metabolic resistance and ACE, the target of OP. ${ }^{34}$ Even though large scale tools to detect those described mutations in the $A a N a_{V} 1011$ and 1016 sites are available ${ }^{35}$ it is necessary to evaluate the $A a N a_{V}$ polymorphism and possible mutations and their actual role in PY resistance in the monitored localities. Herein, we report the analysis of the metabolic resistance and molecular variation in the $A a N a_{V}$ for dengue vector populations of two distinct Brazilian regions.

\section{MATERIALS AND METHODS}

Samples. The Aedes aegypti Rockefeller strain was adopted as the insecticide-susceptible control for biochemical and molecular assays. Aedes aegypti field populations were collected according to recommendations of the Brazilian Aedes aegypti Insecticide Resistance Monitoring Network (MoReNAa), as described elsewhere. ${ }^{36}$ Two other Aedes species, Aedes albopictus and Ochelrotatus fluviatilis (also referred as Aedes fluviatilis), kindly provided by the Laboratório de Transmissores de Hematozoários/ IOC/FIOCRUZ, were adopted for comparison of sodium channel sequences.

Initial analysis of the $A a N a_{V}$ variability was performed with vector populations from cities in Brazilian Southeast (Rio de Janeiro and Nova Iguaçu, both in Rio de Janeiro State) and Northeast (Maceió, in Alagoas State) regions. All other assays were carried out exclusively with populations from Natal (in Rio Grande do Norte State, Northeast Brazil) and Nova Iguaçu (Figure 1). Both are resistant to the larvicide OP temephos and PY used as an adulticide in the country: Natal and Nova Iguaçu populations exhibit temephos $\mathrm{RR}_{95}$ of 12.8 and 18.6, respectively ${ }^{36}$; the pyrethroid cypermethrin kills $59 \%$ and $61.4 \%$ adults from Nova Iguaçu and Natal populations, respectively. ${ }^{37,38}$ For both populations, males and females were used respectively to evaluate $A a N a_{V}$ polymorphism frequency

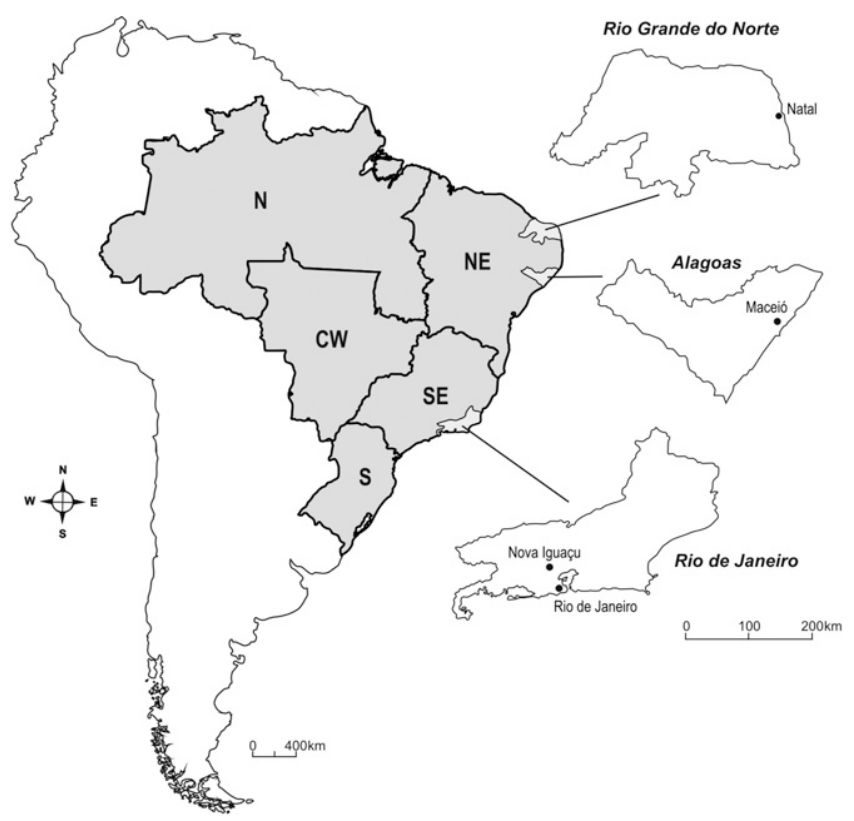

FIGURE 1. Brazilian map. Localization of Brazilian regions and states (light gray and detail) and cities where Aedes aegypti populations were collected, in Northeast (NE) and Southeast (SE) regions. and to perform enzymatic assays to quantify the activity of enzymes involved in metabolic resistance.

Bioassays. Adult females were exposed for 1 hour to $250 \mathrm{~mL}$ glass bottles impregnated with $2 \mu \mathrm{g}$ of cypermethrin (cypermethrin 250CE; Vectocell, São Paulo, Brazil), adapted according to the CDC protocol. The females that survived after a 24 hour recovery period were considered resistant, as previously standardized. ${ }^{37}$

Molecular assays. The DNA from individual adult mosquitoes was extracted in $200 \mu \mathrm{L}$ of "squishing buffer" ( $2 \mathrm{mM}$ EDTA, 0.2\% Triton X-100, and $10 \mathrm{mM}$ Tris- $\mathrm{HCl} \mathrm{pH} 8.2$ ), according to Jowett ${ }^{39}$ with slight modifications. Primers were designed based on the alignment of the IIS6 region, partially encompassing exons 20 and 21, obtained from $A a N a_{V}$ cDNA (GenBank accession no. AF534112) and the Drosophila melanogaster orthologous genomic DNA sequence (GenBank accession no. M32078): 5'-ACAATGTGGATCGCTTCCC-3' and 5'-TGGACAAAAGCAAGGCTAAG-3'.

Molecular analysis was performed in three steps. 1) We aimed to obtain a general picture of the $A a N a_{V}$ polymorphism in Brazilian populations. To accomplish this, DNA pools of 10 females of distinct Ae. aegypti populations were amplified. For each PCR reaction, 4-5 clones (see later) were sequenced. The same was performed with Ae. albopictus and $O$. fluviatilis female mosquitoes. The Ae. aegypti Rockefeller strain was also submitted to the same procedure but with a pool of 100 females and 89 clones. These were analyzed to detect any possible rare variants segregating in the susceptible strain. 2) Our objective was to investigate, in distinct localities, the $A a N a_{V}$ frequency of the sequences previously detected. Two distinct Brazilian localities were chosen (Natal and Nova Iguaçu), and one pool of 405 males was amplified for each population. In both cases, roughly 100 individual clones were analyzed. 3) The $A a N a_{V}$ frequency of distinct sequences was compared between PY resistant and non-resistant mosquitoes. In this case, females of one population (Natal) were exposed to cypermethrin as indicated previously. Pools of respectively 340 and 541 cypermethrin resistant and susceptible females were amplified, approximately 100 clones of each group being analyzed. It is worth mentioning that in all cases, pools were composed of $1 \mu \mathrm{L}$ DNA per individual.

The PCR was conducted in $40 \mu \mathrm{L}$ with high fidelity Pfu polymerase (Biotools, Madrid, Spain), according to manufacturer instructions, supplemented by $1 \mu \mathrm{L}$ of DNA and $1 \mu \mathrm{M}$ of each primer. Reactions were achieved in a termocycler for 3 minutes at $94^{\circ} \mathrm{C}$ for initial denaturation, followed by 35 cycles of $30 \mathrm{~s}$ at $94^{\circ} \mathrm{C}$ for denaturation, $30 \mathrm{~s}$ at $60^{\circ} \mathrm{C}$ for annealing, and $60 \mathrm{~s}$ at $72^{\circ} \mathrm{C}$ for polymerase extension. Electrophoresis of $10 \mu \mathrm{L}$ aliquots of the PCR products in $2.0 \%$ agarose gels confirmed amplification. The PCR products were purified in S-400 microcolumns (GE Healthcare, UK) according to manufacturer instructions and cloned with pMos Blunt ended cloning kit (GE Healthcare, UK). The DNA sequencing was carried out in an ABI377 Sequencer with the Big Dye 3.1 Kit (Applied Biosystems, Warrington, UK). Sequence analysis was performed using the GCG software package (Wisconsin Package version 10.2, Genetics Computer Group [GCG], Madison, WI) and MEGA version 3.1. ${ }^{40}$ Because we sequenced PCR cloned fragments, only changes in at least two sequences were considered, as some of the singletons might represent PCR-induced mutations. Sequences have been submitted to Genbank (accession nos. FJ479609-FJ47615).

Enzymatic assays. Enzymatic assays were performed with snap frozen adult females, one day post emergence to quantify 
GST, Esterases, and ACE activities. Esterases were quantified with three distinct substrates: $\alpha$-naphtyl acetate $(\alpha-\mathrm{NA})$, $\beta$-naphtyl acetate ( $\beta$-NA), and para-nitrophenylacetate ( $p$-NPA). Individual females were analyzed in duplicate for all the enzymes simultaneously, absorbance determined with a ThermoMax microplate reader (Molecular Devices, Sunnyvale, CA). The procedures were precisely the same described elsewhere. ${ }^{34,38}$ Females from the Rockefeller strain were used as the susceptibility control. Enzymatic-specific activities were classified according to already established criteria, for a given population the percentage of specimens with activity higher than percentile 99 of the Rockefeller strain: 0-15\% (unaltered activity), $15-50 \%$ (altered), more than 50\% (highly altered). ${ }^{38}$
Additionally, because all the enzymes were quantified in each individual homogenate, it was possible to perform a posterior correlation analysis.

\section{RESULTS}

Molecular variation in the IIS6 region of $A a N a_{V}$ A fragment, including parts of exons 20 and 21 and the intervening intron of the $A a N a_{V}$ was sequenced from cypermethrin resistant mosquitoes from Brazilian Southeast and Northeast regions as well as those of the susceptible Rockefeller strain. Two types of introns were detected, with pronounced differences in both sequence and size (see alignment in Figure 2).
$\begin{array}{lllllllllllllllllllllllllllllll}I & E & S & M & \text { W } & D & C & M & \text { L } & V & G & D & V & S & C & I & P & F & F & \text { L } & A & \text { T } & \text { V } & \text { V } & \text { I/M } & G & N & \text { L } & \text { V }\end{array}$ TIGR GATCGAATCCATGTGGGATTGTATGCTTGTGGGTGACGTGTCCTGTATTCCGTTCTTTTTGGCCACCGTAGTGATAGGAAATCTAGTAgtaagtattcCg

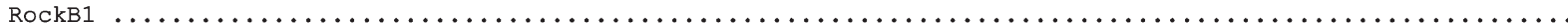

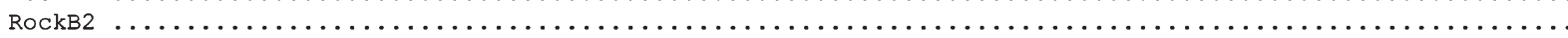

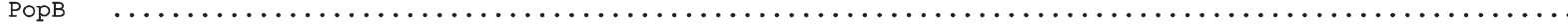

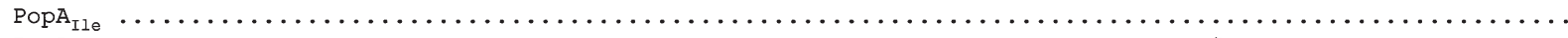

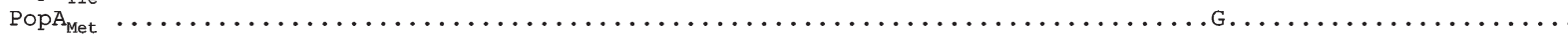

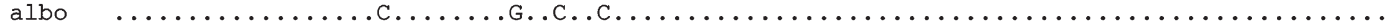

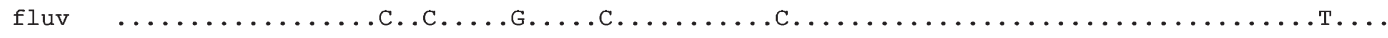

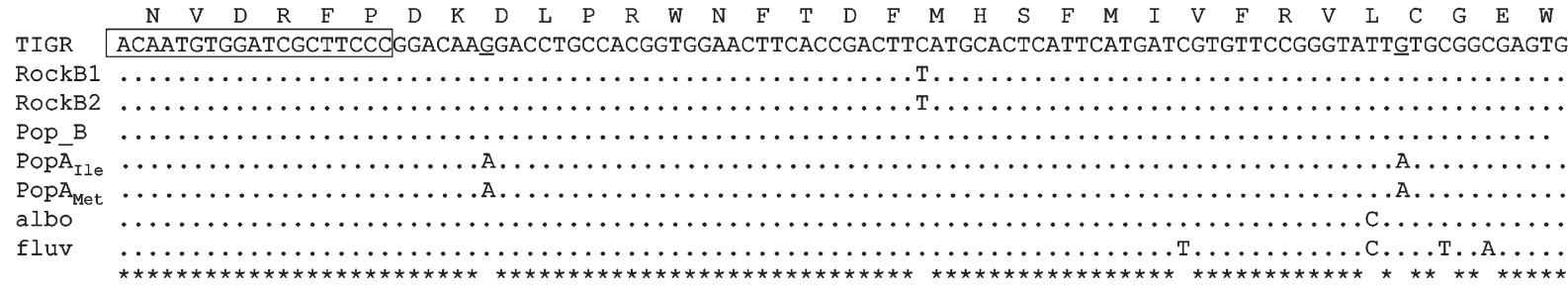

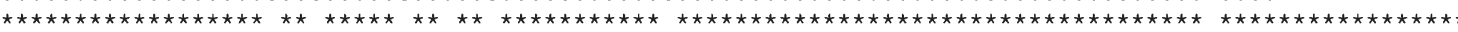

[986]

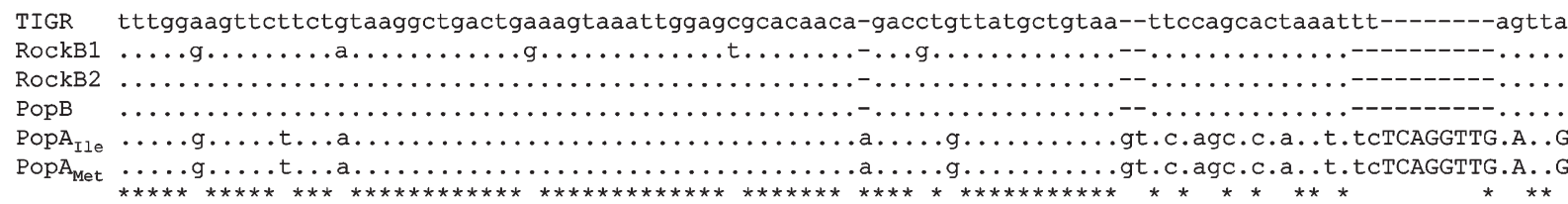

TIGR caaaagaccgtt---gatcttgatagcatcaatattagaggcgtgctagcag-cgacggaggggcgtaccaatttacttttagtcagtctttcttgcatt

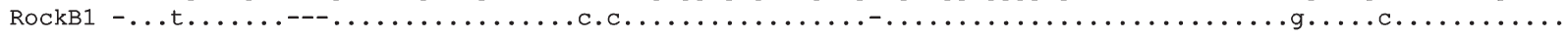

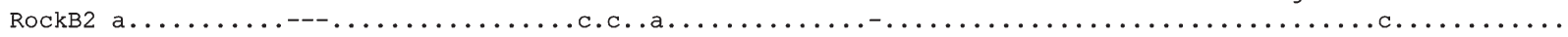

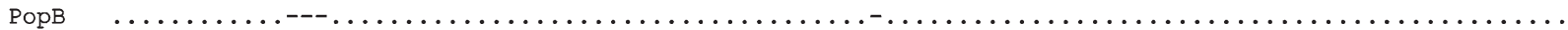
PopA $_{\text {Ile }}$..gt..tt.aa.cgaa...c..-.ctt..t.t.g.t.aca.caa..ct..a..c..ata.aa.a...a.....a.a................ PopA $_{\text {Met }}$.gt..tt.aa.cgaa...c..-.ctt..t.t.g.t.aca.caa..ct..a..c..ata.aa.a...a.....a.a.....c..........

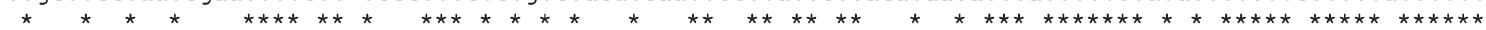

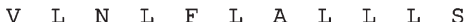

TIGR ctttcgtgctaaccgacaattgtttcccatccgcacagGTACTTAACCTTTTCTTAGCCTTGCTTTTGTCC

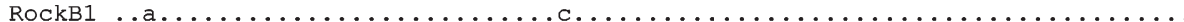

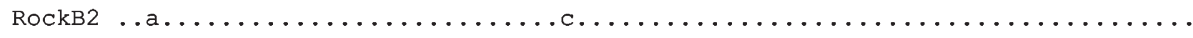

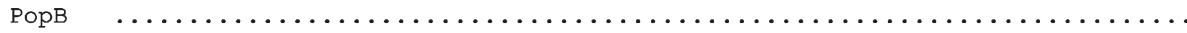

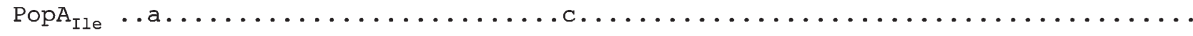

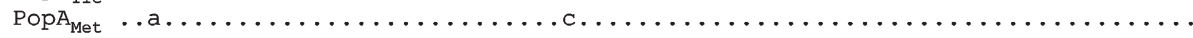

Albo

fluv

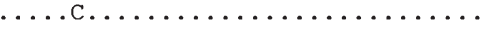

$1026]$

FIGURE 2. Sequence diversity in the AaNa $a_{V}$ IIS6 region of Aedes aegypti, Aedes albopictus, and Aedes fluviatilis strains. Nucleotides in uppercase letters correspond to the coding region; those in lower case refer to the intron. Nucleotide numbering, in parenthesis, at the bottom of each block, refers to the sequence shown in the alignment. The numbering of amino acids (between brackets and at the top of each block) is in accordance with the primary sequence of the VSC1 Musca domestica protein, as usually presented. The site corresponding to the predicted replacement Ile/Met at codon 1011 is in bold. Aedes aegypti sequences were classified as A or B (see text). Sequences were further named Ile or Met according to the amino acid at position 1011. Nucleotides at positions 26 and 89, underlined, are synonymous polymorphic sites that differ between A and B sequences. Only the coding regions of Ae. albopictus (albo) and $O$. fluviatilis (fluvi) are shown. The TIGR corresponds to the sequence obtained from Ae. aegypti genome project, RockB1 and RockB2 are Rockefeller sequences; PopB, Pop $\mathrm{A}_{\mathrm{Ile}}$, and PopA $\mathrm{Aet}_{\mathrm{Met}}$ are sequences of the populations studied here. Boxed regions indicate primer positions. Invariable sites are indicated with *. 
Based on intron length differences, sequences were classified in haplotype groups A (250 pb) and B (234 pb). Additionally, two synonymous transitions $(\mathrm{a} \rightarrow \mathrm{g})$ in exon 20 , positions 26 and 89 , separate the sequences of groups A and B. Rockefeller sequences were all allocated to group B. Additional differences were observed in this strain, and the sequences obtained could be classified in two haplotypes (RockB1 and RockB2) (Figure 2).

Out of 33 sequences from resistant mosquitoes, $72.7 \%$ belong to group A. Although the classic $k d r$ mutation (Leu1014Phe) was not detected, a predicted replacement Ile/Met in the codon 1011 (Ile1011Met) appeared in half of the group A sequences, denominated $\mathrm{A}_{\mathrm{Ile}}$ or $\mathrm{A}_{\mathrm{Met}}$. No amino acid substitution was found in group B sequences. Aedes albopictus and O. fluviatilis exon sequences revealed some synonymous substitutions but no amino acid changes when compared with Ae. aegypti (Figure 2).

Frequency of haplotypes in two field populations. Analysis of $A a N a_{V}$ sequences from Nova Iguaçu and Natal confirmed the polymorphism described previously. Again, the Ile1011Met replacement was only found in group $\mathrm{A}$. Frequencies of the three haplotypes $\left(\mathrm{A}_{\mathrm{Ile}}, \mathrm{A}_{\mathrm{Met}}\right.$, and $\left.\mathrm{B}\right)$ did not differ significantly between Nova Iguaçu and Natal (Table 1), when tested separately or when pooled according to haplotype group (A or B) or amino acid at position 1011 (Ile or Met).

Correlation between haplotypes and pyrethroid resistance. Frequencies of the different $A a N a_{V}$ alleles were evaluated in resistant and susceptible females from Natal. Females were previously selected by pyrethroid exposure, as indicated in the Materials and Methods section. A total of 340 (38.6\%) live (resistant) and 541 (61.4\%) dead (susceptible) females were selected 24 hours after exposure to cypermethrin. We obtained 87 and 73 sequences from resistant and susceptible populations, respectively (Table 2). As before, the only predicted amino acid replacement was the Ile1011Met in sequences belonging to haplotype group A. Frequencies of the haplotypes differed between Natal resistant and susceptible groups (Table 2). Resistant mosquitoes presented higher frequencies of $\mathrm{A}_{\mathrm{Met}}$ and $\mathrm{B}$ when compared with the susceptible group (Figure 3).

Enzymatic assays. The activity profile of Esterases, GSTs, and ACE was analyzed in 1-day-old adult females from Nova Iguaçu and Natal, both highly resistant to the organophosphate temephos. ${ }^{36}$ No alteration in Acetylcholinesterase, the

TABLE 1

Haplotype frequencies in the IIS6 region of $A a N a_{V}$ in two Brazilian populations*

\begin{tabular}{|c|c|c|c|c|c|}
\hline & \multicolumn{2}{|c|}{ Nova Iguaçu } & \multicolumn{2}{|c|}{ Natal } & \multirow[b]{2}{*}{$\chi^{2} ; \mathrm{df} ; P$} \\
\hline & $\mathrm{n}$ & $\mathrm{n} /$ total & $\mathrm{n}$ & $\mathrm{n} /$ total & \\
\hline \multicolumn{5}{|c|}{ Haplotypes } & \multirow[t]{4}{*}{$2.194 ; 2 ; \mathrm{NS}$} \\
\hline $\mathrm{A}_{\text {Ile }}$ & 12 & 0.143 & 6 & 0.073 & \\
\hline $\mathrm{A}_{\mathrm{Met}}^{\mathrm{lle}}$ & 32 & 0.381 & 36 & 0.439 & \\
\hline $\mathrm{B}^{\mathrm{Met}}$ & 40 & 0.476 & 40 & 0.488 & \\
\hline \multicolumn{5}{|c|}{ Haplotypes } & \multirow{4}{*}{$0.0224 ; 1 ; \mathrm{NS}$} \\
\hline (Pooling A & $A_{N}$ & & & & \\
\hline Group A & 44 & 0.524 & 42 & 0.512 & \\
\hline Group B & 40 & 0.476 & 40 & 0.488 & \\
\hline \multicolumn{5}{|c|}{ Amino acid at site1011 } & \multirow[t]{4}{*}{$0.364 ; 1 ; \mathrm{NS}$} \\
\hline Met & 33 & 0.393 & 36 & 0.439 & \\
\hline Ile & 51 & 0.607 & 46 & 0.561 & \\
\hline Total & 84 & & 82 & & \\
\hline
\end{tabular}

* Data show the number of sequences (n) followed by its frequency (n/total), with $\chi^{2}$ value, degrees of freedom $(\mathrm{df})$ and significance $(P)$ at 0.05 level. NS $=$ not significant.
TABLE 2

Haplotype frequencies in the $A a N a V$ IIS6 region in cypermethrin resistant and susceptible mosquitoes from $\mathrm{Natal}^{*}$

\begin{tabular}{|c|c|c|c|c|c|}
\hline & \multicolumn{2}{|c|}{ Natal-R } & \multicolumn{2}{|c|}{ Natal-S } & \multirow[b]{2}{*}{$\chi^{2} ; \mathrm{gl} ; P$} \\
\hline & $\mathrm{n}$ & $\mathrm{n} /$ total & $\mathrm{n}$ & $\mathrm{n} /$ total & \\
\hline \multicolumn{5}{|l|}{ Haplotypes } & \multirow[t]{5}{*}{$28.390 ; 2 ; * * *$} \\
\hline $\mathrm{A}_{\mathrm{Ile}}$ & 7 & 0.080 & 31 & 0.425 & \\
\hline$A^{\text {Ile }}$ & 41 & 0.471 & 28 & 0.384 & \\
\hline B & 39 & 0.448 & 14 & 0.192 & \\
\hline \multicolumn{5}{|c|}{ Haplotypes } & \\
\hline \multicolumn{5}{|c|}{ (Pooling $\mathrm{A}_{\mathrm{Ie}}$ and $\left.\mathrm{A}_{\mathrm{Met}}\right)$} & \multirow[t]{3}{*}{$11.790 ; 1 ; * * *$} \\
\hline Group A & 48 & 0.552 & 59 & 0.808 & \\
\hline Group B & 39 & 0.448 & 14 & 0.192 & \\
\hline \multicolumn{5}{|c|}{ Amino acid at codon 1011} & \multirow[t]{4}{*}{$1.722 ; 1 ; \mathrm{NS}$} \\
\hline Met & 46 & 0.529 & 31 & 0.425 & \\
\hline Ile & 41 & 0.471 & 42 & 0.575 & \\
\hline Total & 87 & & 73 & & \\
\hline
\end{tabular}

* Natal-R and Natal-S indicate, respectively, surviving and dead Natal Ae. aegypti females resulting from 1 in cant; $* * * P<0.001$

target site of organophosphates and carbamates, was detected (Figure 4, Table 3). With exception of Esterase with $\beta$-NA substrate in Nova Iguaçu, increased activity of Esterases was observed in both populations with all three substrates used (Figure 4, Table 3). Correlation analysis of Esterases with $\alpha$-NA and $\beta$-NA substrates displayed high and significant values for Nova Iguaçu, Natal, and Rockefeller (Table 4). The activity of GST was highly increased in both populations. Overall, the assays exhibited higher levels of enzyme activity in mosquitoes from Natal when compared with Nova Iguaçu (Figure 4).

\section{DISCUSSION}

All over the world, chemical insecticides are still the most widely used vector control strategy. Hence, monitoring of insecticide resistance is crucial to the long-term maintenance of this strategic tool. ${ }^{41}$ Increased metabolic detoxification is the most common mechanism of insecticide resistance. ${ }^{10}$ We researched the metabolic resistance mechanisms selected in mosquito populations from distinct localities (Natal and Nova Iguaçu) in Southeast and Northeast Brazil, resistant to the OP temephos and the PY cypermethrin..$^{36-38}$ Activities of Esterases, followed by GST, were altered in both populations. Regarding Esterases, we observed higher activity with substrate $\alpha$-NA than $\beta$-NA. The activity with the $p$-NPA substrate was also high for both populations. Differences of Esterase activity when $\alpha$-NA and $\beta$-NA are used remain unclear, because there

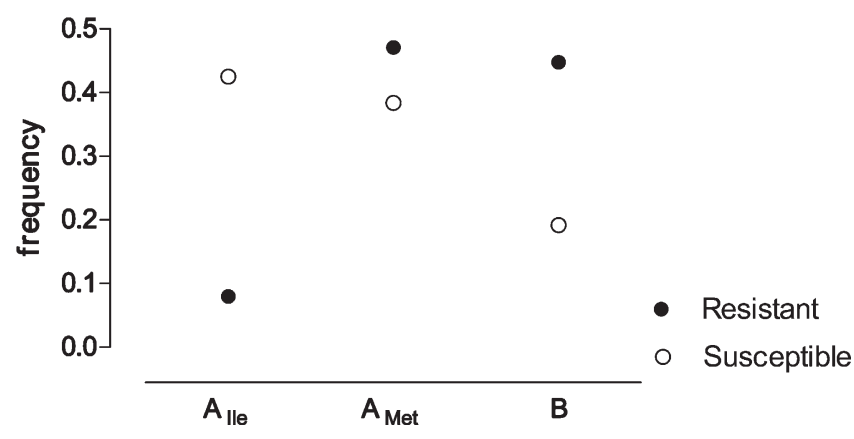

FIgURE 3. Haplotype frequencies in the $\mathrm{AaNaV}$ IIS6 region in cypermethrin resistant and susceptible mosquitoes from Natal. 

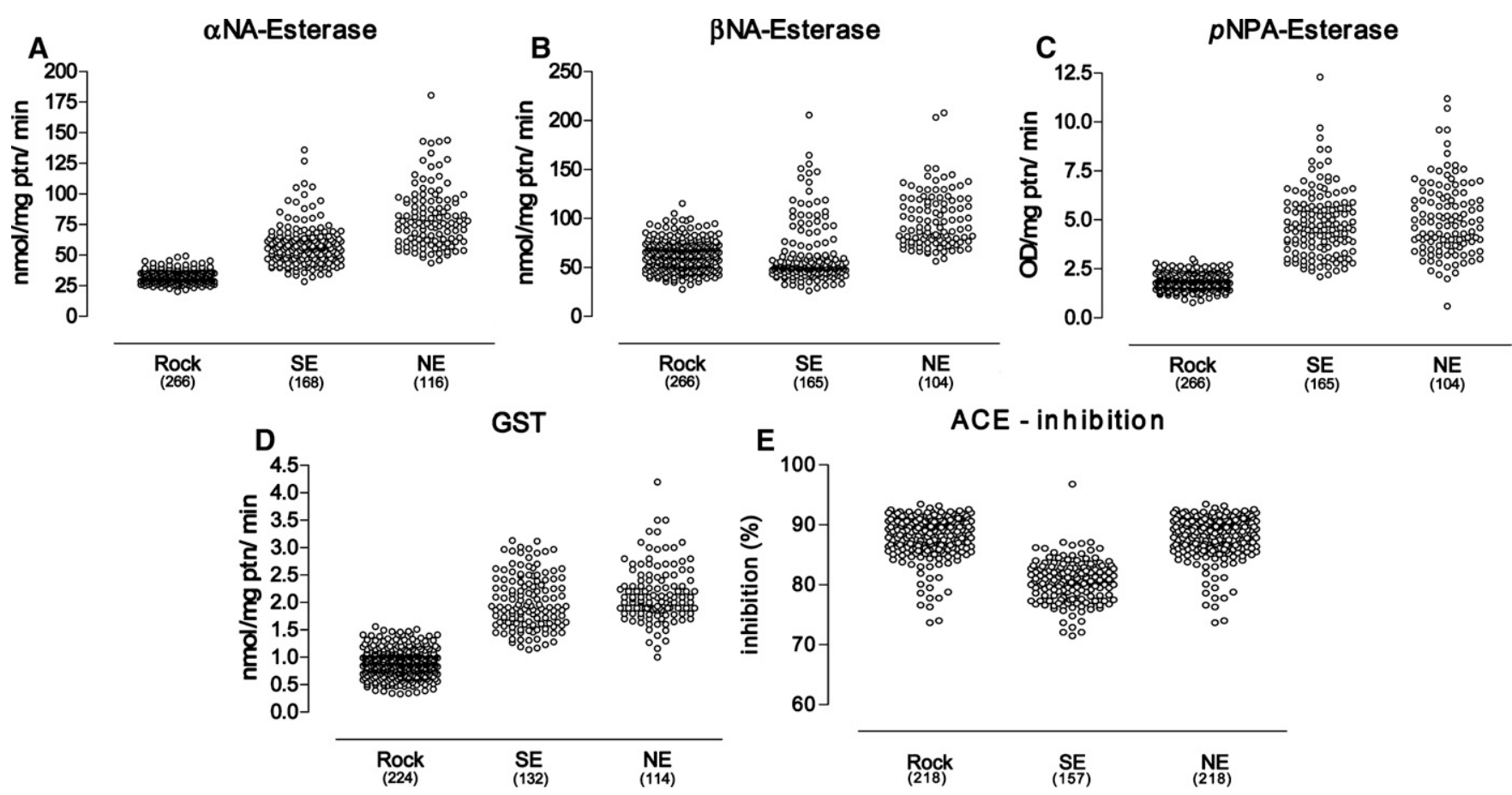

Figure 4. (A-E) The enzymes involved in the metabolic resistance and ACE are shown in the dot graphics for individual mosquitoes. A, B, and $\mathbf{C}$ represent the dot graphic of activity quantification for three different Esterase substrates. D is the quantification for GST enzyme activity and $\mathbf{E}$ to quantify the percentage of ACE inhibition. The number of samples used is indicated under the population name. The Rockefeller strain (Rock) values were used as control of susceptibility.

are high and significant correlations of these activities in both populations as well as in the Rockefeller strain. This suggests that the same substrates ( $\alpha$-NA and $\beta$-NA) are being used by the same enzymes (for further discussions see Reference 38). The existence of different Esterases exhibiting co-regulated expression could also be hypothesized. Interestingly, a significant correlation between $p$-NPA and $\alpha$-NA or $p$-NPA and $\beta$-NA was observed only in the Nova Iguaçu population, suggesting that, compared with Natal, different Esterase might have been selected in that population.

The high Esterase activity with the $p$-NPA substrate in the Nova Iguaçu and Natal populations could be construed as indirect evidence of the Esterase role in PY resistance. This result corroborates a previous report that associates $p$-NPA Esterase activity increase with the introduction of PY in adult mosquito control in the country. ${ }^{10}$ Regardless, PY hydrolysis by Esterase has not been observed in mosquitoes, although it has been experimentally evidenced in some arthropods, such as the tick Boophilus microplus and the aphid Myzus persicae..$^{42,43}$

There has been an increase of GST activity in Nova Iguaçu and Natal populations, which are resistant to both OP and PY. The GST activity has also augmented in Brazilian Ae.

TABLE 3

Frequencies (\%) of specimens in Nova Iguaçu and Natal populations with enzyme activity higher than Rockefeller percentile 99 values*

\begin{tabular}{lcc}
\hline Enzyme assay & Nova Iguaçu & Natal \\
\hline$\alpha$-NA Est & 75.2 & 99.1 \\
$\beta$-NA Est & 12.7 & 44.2 \\
$p$-NPA Est & 92.4 & 93.9 \\
GST & 86.3 & 94.8
\end{tabular}

$*$ The classification criteria follow: $0-15$ (unaltered), $<15-50$ (altered), $>50$ (highly altered) (for these criteria details see Montella and others ${ }^{9}$ ). aegypti populations since PY introduction in field efforts of adult control, suggesting participation of this class of enzymes in PY resistance. ${ }^{38} \mathrm{~A}$ recent microarray analysis with the "Aedes detox chip" indicates higher expression of particular GST genes. ${ }^{44}$ To date, only one gene (GST-2), ${ }^{45}$ out of the 26 known from the GST family has been incriminated as responsible for DDT and permethrin resistance in South American Ae. aegypti populations. ${ }^{46}$ It has already been claimed that another gene, GSTe2, associated with $A e$. aegypti and An. gambiae DDT resistance, might also participate in PY resistance. ${ }^{47}$

Because enzymes associated with metabolic resistance are general detoxifying agents, it was not possible to conclude whether their altered expression observed in Nova Iguaçu and Natal populations was the result of selective pressure with OP or PY. Recently developed procedures, based on quantitative trait loci (QTL) and microarray analyses, will certainly contribute to elucidate the specific Ae. aegypti detoxifying genes selected by PY pressure. .4,48 $^{4}$

Resistance to DDT and PY is linked to the sodium channel gene $\left(N a_{V}\right)$ locus in $A$ e. aegypti ${ }^{19}$ and in a number of other

TABLE 4

Correlation analysis of Esterases activity after quantification with three different substrates*

\begin{tabular}{|c|c|c|c|c|c|c|}
\hline & \multicolumn{3}{|c|}{ Esterase ( $\beta$-NA) } & \multicolumn{3}{|c|}{ Esterase ( $p$-NPA) } \\
\hline & Rock & Nova Iguaçu & Natal & Rock & Nova Iguaçu & Natal \\
\hline Esterase $(\alpha-\mathrm{NA})$ & $\begin{array}{l}0.779 \\
* * *\end{array}$ & $\begin{array}{l}0.815 \\
* * *\end{array}$ & $\begin{array}{l}0.539 \\
* * *\end{array}$ & $\begin{array}{c}-0.019 \\
\text { NS }\end{array}$ & $\begin{array}{l}0.637 \\
* * *\end{array}$ & $\begin{array}{l}0.116 \\
\text { NA }\end{array}$ \\
\hline Esterase ( $\beta$-NA) & & & & $\begin{array}{c}-0.001 \\
\text { NS }\end{array}$ & $\begin{array}{l}0.454 \\
* * *\end{array}$ & $\begin{array}{c}-0.071 \\
\text { NS }\end{array}$ \\
\hline
\end{tabular}

*Numbers represent Pearson correlation indexes. Codes below indicate significance at 0.05 level; NS = not significant; $* * * *<0.001$. 
insect species. ${ }^{27,28}$ In the 1980 s, absence of metabolic changes together with DDT cross-resistance exhibited by some PY resistant Ae. aegypti populations, had already suggested the occurrence of mutations in the target site. ${ }^{49}$ Hitherto, the vast majority of mutations in the $\mathrm{Na}_{V}$ of arthropods conferring resistance to DDT and PY, including the Leu1014Phe classic $k d r$ mutation, occur in the IIS6 hydrophobic domain. ${ }^{27}$

Two mutations in the IIS5-IIS6 inter-segment region of Thai Ae. aegypti populations still remain to be effectively associated to resistance. ${ }^{50}$ The same is true regarding four putative amino acid replacements in the IIS4-S6 segments of $\mathrm{AaNa}_{V}$ detected in Ae. aegypti samples from 13 different regions of the world. ${ }^{29}$ As stated before, the substitution here described (Ile1011Met) has also appeared in a sample from Belém, a city of Pará State, in Northern Brazil. Nevertheless, its correlation with resistance was not confirmed after laboratory PY resistance selection of Mexico and Cuba populations. On the other hand, these authors pointed to a strong association between PY resistance and the Val1016Ile substitution, ${ }^{30}$ not found in the Natal and Nova Iguaçu populations here described.

Based on the intron length polymorphism occurring in the IIS6 domain, the sequences here generated were grouped into two haplotype groups, A and B (Figure 2). Rockefeller, the laboratory strain usually adopted as a susceptible control, exhibited only $\mathrm{B}$ sequences, homologous to the one annotated in the $A e$. aegypti genome project (Vector Based contig 1.186). A recent analysis of the molecular variation in the IIS6 region from some Latin American localities grouped $A a N a_{V}$ sequences in three clades ("1," " 2 ," and " 3 "). ${ }^{30}$ Based on the figure presented in that work, the A sequences should be located in the clade 2 and the B sequences in the clades 1 and 3 .

Brazilian field populations have both haplotypes A and B, but the Ile1011Met replacement was observed only in haplotype A. In Culex mosquitoes, in addition to the classic $k d r$ Leu1014Phe mutation, ${ }^{51}$ there are multiple haplotypes of the $N a_{V}$ associated to PY resistance. ${ }^{52}$ Besides the Leu1014Phe mutation, different $N a_{V}$ haplotypes were also observed in the western flower thrips Frankliniella occidentalis resistant to $\mathrm{PY}^{53}$

Here, although the general profile of the $A a N a_{V}$ haplotypes was distinct in both resistant and susceptible Natal mosquitoes, major differences emerged regarding $\mathrm{A}_{\mathrm{Ile}}$, which was more frequent in the susceptible group and B sequences, present mainly in the resistant group (Figure 3). It is possible that the B haplotype, which lacks amino acid substitutions in the studied fragment, is hitchhiking some replacement in some other region of the gene. Alternatively, haplotype B could be associated to some form of transcriptional or post-transcriptional regulation of $N a_{V}$ expression that would affect the sensitivity to PY. This hypothesis would not be surprising, because such a type of regulation of $N a_{V}$ expression is common in insects. ${ }^{27}$ However, there was no evidence of $A a N a_{V}$ post-transcription regulation related to pyrethroid resistance in the only $A e$. aegypti resistant strain studied hitherto. ${ }^{31}$ In the B. germanica cockroach, RNA editing alters the channel sensitivity to a neurotoxin, ${ }^{54}$ and alternative splice variants exhibit different sensitivities to PY.55 Pyrethroid resistance derived from posttranscriptional regulation of $C x$. quinquefasciatus $N a_{V}$ has also been suggested. ${ }^{52}$

Brazilian populations of Ae aegypti have been reported to be genetically structured with relatively little gene flow among them as well as different levels of insecticide resistance..$^{5,57}$
Therefore, the fact that two localities in Northeast (Natal) and Southeast (Nova Iguaçu) Brazil separated by more than 1,200 miles (more than 1,900 km) share very similar haplotype frequencies in the $A a N a_{V}$, suggests that this polymorphism is under strong balancing selection. We are currently researching the prevalence of different haplotypes in the IIS6 region of the $A a N a_{V}$ in other Brazilian localities and their relative contribution to PY resistance.

Received November 27, 2008. Accepted for publication March 10, 2009.

Acknowledgments: We are grateful to Secretaria de Vigilância em Saúde (SVS) for the intermediation in the collections of Aedes aegypti eggs in the localities here studied and to Ricardo Lourenço de Oliveira from the Laboratório de Transmissores de Hematozoários/ IOC/FIOCRUZ for the donation of Aedes albopictus and Aedes fluviatilis specimens. We also thank José Bento Pereira Lima for bioassays assistance, Priscila Fernandes Medeiros Viana and Isabela Reis Montella de Carvalho for the assistance in the colorimetrical biochemical assays. We are grateful to be able to count on the collaboration of the Plataforma Genômica - Seqüenciamento de DNA/PDTIS-FIOCRUZ. Finally, we thank the English revision performed by Mitchell Raymond Lishon, native of Chicago, IL, USAUCLA, 1969.

Financial support: This work was supported by Secretaria de Vigilância em Saúde/Ministério da Saúde, Programa de Desenvolvimento e Inovação Tecnológica em Saúde Pública/Fundação Oswaldo Cruz, Vice-Presidência de Serviços de Referência e Ambiente/Fundação Oswaldo Cruz, Conselho Nacional de Desenvolvimento Científico e Tecnológico, Financiadora de Estudos e Projetos do Rio de Janeiro, and the Howard Hughes Medical Institute.

Authors' addresses: Ademir Jesus Martins, Jutta Gerlinde Birgitt Linss, and Denise Valle, Laboratório de Fisiologia e Controle de Artrópodes Vetores, Instituto Oswaldo Cruz - FIOCRUZ, Av. Brasil 4365, Rio de Janeiro-RJ, 2104-900, Brazil, Tel: +55-21-2580-6598, and Laboratório de Entomologia, Instituto de Biologia do Exército, Rua Francisco Manuel 102 Benfica, Rio de Janeiro-RJ, 20911-270, Brazil, Tel: +55-21-3895-2247, E-mails: ademirjr@ioc.fiocruz.br, jlinss@ioc.fiocruz.br, and dvalle@ ioc.fiocruz.br. Rachel Mazzei Moura de Andrade Lins and Alexandre Afranio Peixoto, Laboratório de Biologia Molecular de Insetos, Instituto Oswaldo Cruz - FIOCRUZ, Av. Brasil 4365, Rio de Janeiro-RJ, 2104-900, Brazil, Tel: +55-21-3865-8231, E-mails: rlins@ioc.fiocruz.br and apeixoto@fiocruz.br.

\section{REFERENCES}

1. Mackenzie JS, Gubler DJ, Petersen LR, 2004. Emerging flaviviruses: the spread and resurgence of Japanese encephalitis, West Nile and dengue viruses. Nat Med 10: S98-S109.

2. Braga IA, Mello CB, Montella IR, Lima JBP, Junior AJM, Medeiros PFV, Valle D, 2005. Effectiveness of methoprene, an insect growth regulator, against temephos-resistant Aedes aegypti populations from different Brazilian localities, under laboratory conditions. J Med Entomol 42: 830-837.

3. Barrett AD, Higgs S, 2007. Yellow fever: a disease that has yet to be conquered. Annu Rev Entomol 52: 209-229.

4. Townson H, Nathan MB, Zaim M, Guillet P, Manga L, Bos R, Kindhauser M, 2005. Exploiting the potential of vector control for disease prevention. Bull World Health Organ 83: 942-947.

5. Hemingway J, Hawkes NJ, McCarroll L, Ranson H, 2004. The molecular basis of insecticide resistance in mosquitoes. Insect Biochem Mol Biol 34: 653-665.

6. Braga IA, Lima JBP, Soares SD, Valle D, 2004. Aedes aegypti resistance to Temephos during 2001 in several municipalities in the states of Rio de Janeiro, Sergipe, and Alagoas, Brazil. Mem Inst Oswaldo Cruz 99: 199-203.

7. da-Cunha MP, Lima JBP, Brogdon WG, Moya GE, Valle D, 2005. Monitoring of resistance to the pyrethroid cypermethrin in Brazilian Aedes aegypti (Diptera: Culicidae) populations collected between 2001 and 2003. Mem Inst Oswaldo Cruz 100: 441-444. 
8. Lima JBP, da-Cunha MP, Da Silva RC, Galardo AKR, Soares SD, Braga IA, Ramos RP, Valle D, 2003. Resistance of Aedes aegypti to organophosphates in several municipalities in the state of Rio de Janeiro and Espirito Santo, Brazil. Am J Trop Med Hyg 68: 329-333.

9. Montella IR, Martins AJ, Viana-Medeiros PF, Lima JBP, Braga IA, Valle D, 2007. Insecticide resistance mechanisms of Brazilian Aedes aegypti populations from 2001 to 2004. Am J Trop Med Hyg 77: 467-477.

10. Hemingway J, Ranson H, 2000. Insecticide resistance in insect vectors of human disease. Annu Rev Entomol 45: 371-391.

11. Busvine JR, 1951. Mechanism of resistance to insecticide in houseflies. Nature 168: 193-195.

12. Milani R, 1954. Comportamento mendeliano della resistenza alla azione abbatante del DDT: correlazione tran abbatimento e mortalia in Musca domestica L. Riv Parassitol 15: 513-542.

13. Harrison CM,1951. Inheritance of resistance to DDT in the housefly, Musca-Domestica L. Nature 167: 855-856.

14. Knipple DC, Doyle KE, Marsellaherrick PA, Soderlund DM,1994. Tight genetic-linkage between the $\mathrm{kdr}$ insecticide resistance trait and a voltage-sensitive sodium-channel gene in the house fly. Proc Natl Acad Sci USA 91: 2483-2487.

15. Williamson MS, Denholm I, Bell CA, Devonshire AL, 1993. Knockdown resistance (kdr) to DDT and pyrethroid insecticides maps to a sodium channel gene locus in the housefly (Musca domestica). Mol Gen Genet 240: 17-22.

16. McDonald PT, Schmidt CD, 1990. Linkage, expression, and distribution of the pyrethroid resistance gene in the horn fly (Diptera: Muscidae). J Econ Entomol 83: 1718-1722.

17. Taylor MFJ, Heckel DG, Brown TM, Kreitman ME, Black B, 1993. Linkage of pyrethroid insecticide resistance to a sodium-channel locus in the tobacco budworm. Insect Biochem Mol Biol 23: $763-775$.

18. Dong K, Scott JG, 1994. Linkage of kdr-type resistance and the para-homologous sodium channel gene in german cockroaches (Blattella germanica). Insect Biochem Mol Biol 24: 647-654.

19. Severson DW, Anthony NM, Andreev O, ffrench-Constant RH, 1997. Molecular mapping of insecticide resistance genes in the yellow fever mosquito (Aedes aegypti). J Hered 88: 520-524.

20. Catterall WA, 2000. From ionic currents to molecular mechanisms: the structure and function of voltage-gated sodium channels. Neuron 26: 13-25.

21. ffrench-Constant RH, Pittendrigh B, Vaughan A, Anthony N, 1998. Why are there so few resistance-associated mutations in insecticide target genes? Philos Trans R Soc Lond B Biol Sci 353: $1685-1693$.

22. Soderlund DM, Knipple DC, 2003. The molecular biology of knockdown resistance to pyrethroid insecticides. Insect Biochem Mol Biol 33: 563-577.

23. Jamroz RC, Guerrero FD, Kammlah DM, Kunz SE, 1998. Role of the $\mathrm{kdr}$ and super-kdr sodium channel mutations in pyrethroid resistance: correlation of allelic frequency to resistance level in wild and laboratory populations of horn flies (Haematobia irritans). Insect Biochem Mol Biol 28: 1031-1037.

24. Anstead JA, Williamson MS, Eleftherianos L, Denholm I, 2004. High-throughput detection of knockdown resistance in Myzus persicae using allelic discriminating quantitative PCR. Insect Biochem Mol Biol 34: 871-877.

25. Bass C, Nikou D, Donnelly MJ, Williamson MS, Ranson H, Ball A, Vontas J, Field LM, 2007. Detection of knockdown resistance (kdr) mutations in Anopheles gambiae: a comparison of two new high-throughput assays with existing methods. Malar J 6: 1-14.

26. Kulkarni MA, Rowland M, Alifrangis M, Mosha FW, Matowo J, Malima R, Peter J, Kweka E, Lyimo I, Magesa S, Salanti A, Rau ME, Drakeley C, 2006. Occurrence of the leucine-to-phenylalanine knockdown resistance (kdr) mutation in Anopheles arabiensis populations in Tanzania, detected by a simplified high-throughput SSOP-ELISA method. Malar J 5: 56.

27. Davies TGE, Field LM, Usherwood PNR, Williamson MS, 2007. DDT, pyrethrins, pyrethroids and insect sodium channels. IUBMB Life 59: 151-162.

28. Soderlund DM, Knipple DC, 2003. The molecular biology of knockdown resistance to pyrethroid insecticides. Insect Biochem Mol Biol 33: 563-577.

29. Brengues C, Hawkes NJ, Chandre F, McCarroll L, Duchon S, Guillet P, Manguin S, Morgan JC, Hemingway J, 2003. Pyre- throid and DDT cross-resistance in Aedes aegypti is correlated with novel mutations in the voltage-gated sodium channel gene. Med Vet Entomol 17: 87-94.

30. Saavedra-Rodriguez K, Urdaneta-Marquez L, Rajatileka S, Moulton M, Flores AE, Fernandez-Salas I, Bisset J, Rodriguez M, Mccall PJ, Donnelly MJ, Ranson H, Hemingway J, Black WC, 2007. A mutation in the voltage-gated sodium channel gene associated with pyrethroid resistance in Latin American Aedes aegypti. Insect Mol Biol 16: 785-798.

31. Chang C, Shen WK, Wang TT, Lin YH, Hsu EL, Dai SM, 2009. A novel amino acid substitution in a voltage-gated sodium channel is associated with knockdown resistance to permethrin in Aedes aegypti. Insect Biochem Mol Biol 39: 272-278.

32. Brogdon WG, McAllister JC, 1998. Simplification of adult mosquito bioassays through use of time-mortality determinations in glass bottles. J Am Mosq Control Assoc 14: 159-164.

33. Hemingway J, 1998. Techniques to Detect Insecticide Resistance Mechanisms (Field and Laboratory Manual). Geneva: World Health Organization.

34. Valle D, Montella IR, Medeiros PFV, Ribeiro RA, Martins AJ, Lima JBP, 2006. Metodologia para quantificação de atividade de enzimas relacionadas com a resistência a inseticidas em Aedes aegypti/Quantification methodology for enzyme activity related to insecticide resistance in Aedes aegypti. First edition. DF: Brasília.

35. Rajatileka S, Black WC, Saavedra-Rodriguez K, Trongtokit Y, Apiwathnasorn C, Mccall PJ, Ranson H, 2008. Development and application of a simple colorimetric assay reveals widespread distribution of sodium channel mutations in Thai populations of Aedes aegypti. Acta Trop 108: 54-57.

36. Lima JBP, da-Cunha MP, Da Silva RC, Galardo AKR, Soares SD, Braga IA, Ramos RP, Valle D, 2003. Resistance of Aedes aegypti to organophosphates in several municipalities in the state of Rio de Janeiro and Espirito Santo, Brazil. Am J Trop Med Hyg 68: 329-333.

37. da-Cunha MP, Lima JBP, Brogdon WG, Moya GE, Valle D, 2005. Monitoring of resistance to the pyrethroid cypermethrin in Brazilian Aedes aegypti (Diptera: Culicidae) populations collected between 2001 and 2003. Mem Inst Oswaldo Cruz 100: 441-444.

38. Montella IR, Martins AJ, Viana-Medeiros PF, Lima JBP, Braga IA, Valle D, 2007. Insecticide resistance mechanisms of Brazilian Aedes aegypti populations from 2001 to 2004. Am J Trop Med Hyg 77: 467-477.

39. Jowett T, 1986. Preparation of nucleic acids. Roberts DB, ed. Drosophila: A Practical Approach. Oxford: IRL, 275-286.

40. Kumar S, Tamura K, Nei M, 2004. MEGA3: integrated software for molecular evolutionary genetics analysis and sequence alignment. Brief Bioinform 5: 150-163.

41. ffrench-Constant RH, 2005. Something old, something transgenic, or something fungal for mosquito control? Trends Ecol Evol 20: $577-579$.

42. Devonshire AL, Moores GD, 1982. A carboxylesterase with broad substrate specificity causes organophosphorus, carbamate and pyrethroid resistance in peach-potato aphids (Myzus persicae). Pestic Biochem Physiol 18: 235-246.

43. Hernandez R, Guerrero FD, George JE, Wagner GG, 2002. Allele frequency and gene expression of a putative carboxylesteraseencoding gene in a pyrethroid resistant strain of the tick Boophilus microplus. Insect Biochem Mol Biol 32: 1009-1016.

44. Strode C, Wondji CS, David JP, Hawkes NJ, Lumjuan N, Nelson DR, Drane DR, Karunaratne SH, Hemingway J, Black WC 4th, Ranson H, 2008. Genomic analysis of detoxification genes in the mosquito Aedes aegypti. Insect Biochem Mol Biol 38: $113-123$.

45. Lumjuan N, Stevenson BJ, Prapanthadara LA, Somboon P, Brophy PM, Loftus BJ, Severson DW, Ranson H, 2007. The Aedes aegypti glutathione transferase family. Insect Biochem Mol Biol 37: 1026-1035.

46. Grant DF, Hammock BD, 1992. Genetic and molecular evidence for a trans-acting regulatory locus controlling glutathione $S$-transferase-2 expression in Aedes aegypti. Mol Gen Genet 234: 169-176.

47. Lumjuan N, McCarroll L, Prapanthadara LA, Hemingway J, Ranson H, 2005. Elevated activity of an Epsilon class glutathione transferase confers DDT resistance in the dengue vector, Aedes aegypti. Insect Biochem Mol Biol 35: 861-871. 
48. Savedra-Rodriguez K, Strode C, Suarez AF, Salas IF, Ranson H, Hemingway J, Black WC IV, 2008. QTL mapping of genome regions controlling permethrin resistance in the mosquito Aedes aegypti. Genetics 180: 1137-1152.

49. Hemingway J, Boddington RG, Harris J, Dunbar SJ, 1989. Mechanisms of insecticide resistance in Aedes aegypti (L) (Diptera: Culicidae) from Puerto-Rico. Bull Entomol Res 79: 123-130.

50. Yaicharoen R, Kiatfuengfoo R, Chareonviriyaphap T, Rongnoparut $\mathrm{P}, 2005$. Characterization of deltamethrin resistance in field populations of Aedes aegypti in Thailand. J Vector Ecol 30: 144-150.

51. Martinez-Torres D, Chevillon C, Brun-Barale A, Berge JB, Pasteur N, Pauron D, 1999. Voltage-dependent Na+ channels in pyrethroidresistant Culex pipiens L mosquitoes. Pestic Sci 55: 1012-1020.

52. Xu Q, Wang HC, Zhang L, Liu NN, 2006. Kdr allelic variation in pyrethroid resistant mosquitoes, Culex quinquefasciatus (S.). Biochem Biophys Res Commun 345: 774-780.

53. Forcioli D, Frey B, Frey JF, 2002. High nucleotide diversity in the para-like voltage-sensitive sodium channel gene sequence in the western flower thrips (Thysanoptera: Thripidae). J Econ Entomol 95: 838-848.

54. Liu ZQ, Song WZ, Dong K, 2004. Persistent tetrodotoxin-sensitive sodium current resulting from U-to-C RNA editing of an insect sodium channel. Proc Natl Acad Sci USA 101: 11862-11867.

55. Du YZ, Liu ZQ, Nomura Y, Khambay B, Dong K, 2006. An alanine in segment 3 of domain III (IIIS3) of the cockroach sodium channel contributes to the low pyrethrold sensitivity of an alternative splice variant. Insect Biochem Mol Biol 36: 161-168.

56. da Costa-Ribeiro MCV, Lourenco-De-Oliveira R, Failloux AB, 2007. Low gene flow of Aedes aegypti between dengue-endemic and dengue-free areas in southeastern and southern Brazil. Am J Trop Med Hyg 77: 303-309.

57. Padua KD, Araujo JP, Ribolla PEM, 2006. Genetic variability in geographical populations of Aedes aegypti (Diptera: Culicidae) in Brazil elucidated by molecular markers. Genet Mol Biol 29: 391-395. 